\title{
Pengaruh Variasi Temperatur dan Reduksi Penampang pada Pembuatan Al-Abu Dasar Batubara terhadap Laju Keausan
}

\author{
Maula Nafi ${ }^{1)}$, Ichlas Wahid ${ }^{2)}$ \\ 1), 2) Teknik Mesin, Universitas 17 Agustus 1945 Surabaya \\ E-mail: ${ }^{1)}$ maula.nafi@untag-sby.ac.id,${ }^{2}$ ichlaswahid@untag-sby.ac.id
}

\begin{abstract}
Abstrak
Proses deformasi akan mengakibatkan peningkatan kekuatan logam yang akan terjadi tergantung seberapa besar deformasi atau regangan yang akan diterima oleh benda kerja. Penelitian ini bertujuan untuk mengetahui pengaruh variasi temperatur $150^{\circ} \mathrm{C}, 160^{\circ} \mathrm{C}, 170^{\circ} \mathrm{C}$ dan reduksi penampang $5 \%, 10 \%, 15 \%$ pada proses penempaan dan sebelum proses penempaan pada komposit Al 2xxx (piston bekas) paduan abu dasar batubara terhadap laju keausan dan strukturmikro. Hasil uji keausan dapat dilihat bahwa variasi temperatur dan reduksi penampang sangat berpengaruh terhadap ketahanan aus yakni dengan nilai laju keausan terendah pada sepesimen dengan variasi temperatur $170^{\circ} \mathrm{C}$ dan reduksi penampang $15 \%$ dengan hasil $0,004 \mathrm{x}$ $10^{-6} \mathrm{~mm}^{3} / \mathrm{mm}$, untuk struktur mikronya membuat ukuran butirnya semakin kecil yakni dengan ukuran diameter rata-rata butir terendah pada sepesimen dengan variasi temperatur $170^{\circ} \mathrm{C}$ dan reduksi penampang $15 \%$ dengan hasil $133,3 \mu \mathrm{m}$ berbanding terbalik dengan sebelum proses penempaan dimana ketahanan ausnya sangat rendah dengan nilai laju keausan pada spesimen sangat tinggi dengan hasil $0,054 \times 10-6 \mathrm{~mm}^{3} / \mathrm{mm}$ dan struktur mikronya membuat ukuran butir dengan hasil $257,56 \mu \mathrm{m}$. Hal ini menunjukan bahwa semakin besar temperatur dan reduksi penampang pada proses penempaan aluminium $2 \times x x$ (piston bekas) paduan abu dasar batubara dapat meningkatkan sifat mekaniknya.
\end{abstract}

Kata Kunci: Komposit Al-Abu Dasar Batu Bara, Laju Keausan, Pelat, Penempaan, Reduksi Penampang.

\begin{abstract}
The deformation process will result in an increase in metal strength that will occur depending on how much deformation or strain will be received by the workpiece. The objective of this study is to determine the effect of temperature variations of $150^{\circ} \mathrm{C}$, $160^{\circ} \mathrm{C}, 170^{\circ} \mathrm{C}$ and reduction of cross section $5 \%, 10 \%, 15 \%$ in the forging process and before the forging process on Al $2 x x x$ composites (used piston) coal bottom-ash alloys on the wear rate and microstructure. The wear test results can be seen that the temperature variation and cross section reduction greatly affect the wear resistance with the lowest wear rate in specimens with $170^{\circ} \mathrm{C}$ temperature variations and $15 \%$ cross section reduction with the result of $0.004 \times 10^{-6} \mathrm{~mm}^{3} / \mathrm{mm}$, for the microstructure making the grain size increasingly small ie with the lowest average grain size in specimens with a temperature variation of $170^{\circ} \mathrm{C}$ and a reduction of $15 \%$ cross section with a result of $133.3 \mu \mathrm{m}$ inversely proportional to before the forging process where the wear resistance is very low with a wear rate value on the specimen is very high with a result of $0.054 \times 10^{-6} \mathrm{~mm}^{3} / \mathrm{mm}$ and the microstructure makes a grain size with a yield of $257.56 \mu \mathrm{m}$. This shows that the greater the temperature and reduction of the cross section in the forging process of aluminum $2 x x x$ (used piston) coal bottom ash alloy can improve its mechanical properties.
\end{abstract}


Keywords : Area Reduction, Composite Plate of Al-Bottom Ash Coal, Forging, Mictostructure, Temperature, Wear Rate.

\section{PENDAHULUAN}

Permasalahan yang sering dialami oleh dunia industri adalah bagaimana cara meminimalisir kerugian keausan atau membuat material alternatif baru terjadi pada dua komponen mesin saling menekan dan saling bergesekan. Keausan jenis ini terjadi apabila suatu partikel keras (asperity) dari material tertentu meluncur pada permukaan material lain yang lebih lunak sehingga terjadi penetrasi atau pemotongan material yang lebih lunak.Tingkat keausan pada mekanisme ini ditentukan oleh derajat kebebasan (degree of freedom) partikel keras atau asperity tersebut. Keausan paling besar terjadi pada benda - benda lunak.Faktor - faktor yang yang mempengaruhi keausan adalah kecepatan, tekanan, kekasaran permukaan dan kekerasan material [1]. MMC (komposit matriks logam) adalah logam yang diperkuat dengan logam lain, keramik atau senyawa organik [2].

Setiawan dalam penelitiannya mengatakan pembuatan komposit aluminium 2075 diperlukan sebuah penguat berupa abu dasar batu bara yang telah melalui proses elektroles yang berfungsi melapisi serbuk abu dasar batu bara agar menempel pada logam aluminium saat pengecoran[3]. Menurut Ahmad abu dasar batubara (bottomash) memiliki kandungan $\mathrm{SiO}_{2}$ yang diperkirakan sebesar 41,73\% dan kandungan $\mathrm{Al}_{2} \mathrm{O}_{3}$ berkisar 24,3\% yang jumlahnya melimpah, tingkat kekerasan yang tinggi, tahan terhadap suhu tinggi dengan titik leleh diatas $2000^{\circ} \mathrm{C}$ dan murah sehingga dapat digunakan sebagai bahan penguat pada logam komposit alumunium[4]. Dalam penelitian Wibowo Aluminium 6061-T6 mempunyai keunggulan seperti kekuatan tarik relatif tinggi, sifat mampu bentuk (formability) baik, tahan korosi dan merupakan logam ringan. Menurut penelitian Nafi, menyimpulkan bahwa adanya peningkatan nilai sifat mekanik, yaitu kekerasan dan kekuatan pada material komposit Al-Abu dasar batu bara setelah diberikan perlakuan panas T6[5]. Sama halnya teori Isranuri, kekerasan suatu material sangatlah mempengaruhi ketahanan aus suatu material [6]. Ukuran butir abrasif memberikan efek terbesar pada keausan. Meningkatnya temperatur piringan mempercapat laju keausan[7]. Menurut Santoso, pengaruh temperatur tempering 
terhadap kekerasan dan struktur mikro adalah semakin tinggi temperatur tempering[8], maka kekerasan akan menurun dan struktur mikro yang terbentuk adalah tempered martensit dan senyawa karbida. Dari hasil penelitian Rusianto pada foto strukturmikro terlihat bahwa aluminium berwarna putih keabuan dan yang terlihat berwarna hitam pada struktur mikro merupakan porositas. Persentase rata-rata porositas mengalami penurunan dengan meningkat[9]. Dari hasil perhitungan berat jenis bahwa bushing mengalami kenaikan dengan meningkatnya suhu hot pressing begitu pula setelah proses sinter. Pada pengujian kekerasan diketahui bahwa kekerasan bushing semakin meningkat dan laju keausan dari hasil pengujian keausan diketahui bahwa keausan bushing semakin menurun dengan meningkatnya suhu hot pressing.

Dari uraian latar belakang diatas, terdapat sebuah permasalahan hingga diperlukannya penelitian dengan objek yaitu variasi temperatur dan reduksi penampang pada pembuatan pelat terhadap laju keausan dan struktur mikro komposit Al 2xxx (piston bekas) dengan penguat abu dasar batubara (bottomash) dengan metode pembuatan gravity casting. Dalam penelitian ini, menggunakan bahan komposit Al 2xxx (piston bekas) dengan penguat abu dasar batubara dan metode pembuatannya gravity casting dengan menvariasikan temperatur dan reduksi penampang untuk mengatahui ketahanan pada laju keausan dan struktur mikro.

\section{METODE PENELITIAN}

a. Preparasi

Mempersiapkan alat dan bahan dimulai dengan mengumpulkan alumunium $2 \mathrm{xxx}$ (piston bekas berbagai merek) didapat dari bengkel-bengkel di daerah Surabaya, serbuk alumunium (Al), serbuk magnesium $(\mathrm{Mg})$, larutan $\mathrm{HNO}_{3} 65 \%$ dan alkhohol teknik $95 \%$ didapat dari UD.Sumber Ilmiah Persada Surabaya dan abu dasar (bottom ash) batubara diperoleh dari sisa pembakaran batubara didapat dari PT. Smart.Tbk di daerah Rungkut Industri, Surabaya. Kemudian abu dasar batubara yang masih kasar dipisahkan dari pasir dan kotoran lain yang masih tercampur, abu dasar(bottom ash) batubara yang sudah dipisahkan lalu digiling hingga halus kemudian disaring kembali dengan saringan ukuran 350 mesh.

\section{b. Proses Electroless Plating}

Proses Electroless plating adalah salah satu metode pelapisan dengan cara 
membasahi dan melapisi serbuk abu dasar batu bara (bottom ash) yang bertujuan agar mudah berinfiltrasi dengan alumunium pada saat pengecoran. Dimulai dengan menimbang abu dasar batubara (200gr), aluminium murni (0,5gr), alumunium oksida (40 gr) dan magnesium (0,1 gr) harus sesuai dengan kapasitas gelas erlenmayer dan pengaduk magnetic stirrer.

Setelah menimbang bahan dilanjutkan dengan kalsinasi pada abu dasar batubara dengan temperatur $100^{\circ} \mathrm{C}$ dengan waktu 3 jam dan menakar larutan $\mathrm{HNO}_{3}$ konsentrasi $65 \%$ sebanyak $120 \mathrm{ml}$. Proses electroless plating dengan mencampurkan abu dasar batubara, aluminium murni dan $\mathrm{HNO}_{3}$ konsentrasi $65 \%$ yang sudah ditimbang/ditakar, kedalam gelas erlenmayer secara berurutan kemudian nyalakan pemanas kompor magnetic. Letakkan diatas kompor magnetik dan atur sampai temperatur $100^{\circ} \mathrm{C}$ dan diaduk sampai merata selama 5 menit dengan menggunakan magnetic stirrer. Masukkan magnesium secara perlahan sambil diaduk selama 1 jam, setelah larutan agak mengering dengan temperatur $100^{\circ} \mathrm{C}$ dilanjutkan dengan proses oksidasi dengan cara dikeringkan didalam oven pada temperatur $300^{\circ} \mathrm{C}$ selama 3 jam.

c. Proses Pengecoran Komposit Dengan Metode Gravity Casting

Dimulai dengan menimbang bahan sesuai dengan komposisi yang dibutuhkan sebanyak 13,6 kg dimana dibutuhkan 2 coran dari setiap volume coran $2520 \mathrm{~cm}^{3}$ dengan persentase tiap bahan (Abudasar Batu Bara yang telah di electroless plating 1.360 gr, Magnesium 136 gr dan Piston Bekas 12,1 Kg) kemudian bungkus dan beri label atau tanda pada setiap jenis bahan yang sudah ditimbang agar tidak tertukar.

Dalam proses pengecoran, diawali dengan menyalakan burner untuk proses pemanasan kemudian masukkan aluminium kedalam kowi peleburan sebanyak 6,8 $\mathrm{kg}$ dan panaskan aluminium kedalam tungku pelebur sampai titik cair $660^{\circ} \mathrm{C}$. Setelah sampai temperatur $660^{\circ} \mathrm{C}$, tambahkan abu dasar batubara yang sudah dielecroless plating $\left(\mathrm{MgSiO}_{2}\right)$ dan magnesium kedalam aluminium yang sudah cair secara perlahan dengan komposisi massa bahan yang sudah disiapkan sebelumnya sambil diaduk secara merata. Sebelum cairan dituangakan kedalam cetakan, panaskan cetakan terlebih dahulu agar tidak terjadi porosity pada logam yang akan dituangkan. Setelah temperatur mencapai $700^{\circ} \mathrm{C}$ tuang logam cair kedalam cetakan. Setelah membentuk coran komposit (As-Cast) yang padat cetakan dilepas dan 
didinginkan pada suhu kamar dan dilakukan secara bertahap.

\section{d. Homogenizing}

Proses ini bertujuan untuk menghilangkan efek segregasi kimia akibat proses pembekuan yang lambat pada saat proses pengecoran komposit dan untuk memperbaiki mampu pengerjaan panas (hot workability) dengan temperatur $125^{\circ} \mathrm{C}$ dengan waktu tahan 120 menit.

e. Proses Penempaan (Forging)

Pada proses ini setelah material coran komposit (As-Cast) di proses permesinan, maka selanjutnya material dilakukan tahap proses pembentukan dengan cara penempaan untuk membentuk lempengan pelat komposit dengan temperatur $150^{\circ} \mathrm{C}, 160^{\circ} \mathrm{C}, 170^{\circ} \mathrm{C}$ dan direduksi penampang $5 \%, 10 \%, 15 \%$ dari ukuran material coran komposit (As-Cast) setelah permesinan. Proses penempaan dimulai dengan memanaskan bahan sesuai dengan variasi temperatur yaitu $150^{\circ} \mathrm{C}, 160^{\circ} \mathrm{C}, 170^{\circ} \mathrm{C}$ kemudian melakukan proses reduksi penampang dengan cara di press sesuai ukuran yaitu $5 \%, 10 \%, 15 \%$.

\section{f. Proses Pemesinan Membuat Spesimen Uji}

Proses permesinan dibutuhkan untuk membuat spesimen sesuai mesin uji dengan menentukan ukuran yang akan di buat. Untuk ukuran spesimen uji keausan adalah $\mathrm{P}: 30 \mathrm{~mm}, \mathrm{~L}: 20 \mathrm{~mm}$ dan $\mathrm{T}: 4 \mathrm{~m}$ dan ukuran spesimen pengamatan strukturmikro adalah D : $10 \mathrm{~mm}$ dan $\mathrm{T}: 15 \mathrm{~mm}$, Pemotongan dan pembentukan pelat komposit sesuai dengan dimensi yang sudah ditentukan untuk spesimen uji (30 spesimen uji).

\section{g. Proses Perlakuan Panas T6}

Proses perlakuan panas T6 merupakan penuaan keras (age hardening). Melalui penuaan keras, logam paduan alumunium akan memperoleh kekuatan dan kekerasan yang lebih baik. Dimulai dengan melakukan pelarutan (Solution treatment) yaitu spesimen uji dipanaskan pada temperatur $450^{\circ} \mathrm{C}$ dan ditahan selama 120 menit kemudian didinginkan cepat (Quenching) dengan air garam sebagai media pendingin kemudian dipanaskan kembali (Aging) sampai suhu $125^{\circ} \mathrm{C}$ ditahan 60 menit kemudian didinginkan dengan suhu kamar didalam dapur.

\section{h. Proses Uji Keausan}


Pengujian keausan dilakukan untuk mengetahui laju keausan. Spesimen mendapat beban gesekan dari disk berdiameter $28 \mathrm{~mm}$ yang berputar (revolving disc) selama 1 menit. Kontak antar permukaan antara disc dan permukaan spesimen akan menghasilkan jejak bekas gesekan, besar jejakan tersebut yang kemudian dijadikan dasar penentuan nilai keausan.

i. Proses Pengamatan Strukturmikro

Proses pengamatan strukturmikro ini bertujuan untuk mengetahui kumpulan fasa-fasa yang dapat diamati melalui teknik metalografi dan dari struktur mikro kita dapat melihat ukuran dan menghitung besar butir dengan Standard ASTM E112. Metalografi merupakan suatu metode untuk menyelidiki struktur logam dengan menggunakan mikroskop optik dan mikroskop elektron. Sedangkan struktur yang terlihat pada mikroskop tersebut tersebut disebut mikrostruktur[8]. Pengamatan tersebut dilakukan terhadap spesimen yang telah diproses sehingga bisa diamati dengan pembesaran tertentu.

\section{HASIL DAN PEMBAHASAN}

Tabel 1. Kodefikasi spesimen

\begin{tabular}{|c|c|c|c|}
\hline $\begin{array}{r}\text { Reduksi } \\
\text { Temperatur }\end{array}$ & $5 \%$ & $10 \%$ & $15 \%$ \\
\hline $150^{\circ} \mathrm{C}(\mathrm{a})$ & $\mathrm{A} 1(\mathrm{a})$ & $\mathrm{B} 1(\mathrm{a})$ & $\mathrm{C} 1(\mathrm{a})$ \\
\hline $150^{\circ} \mathrm{C}(\mathrm{b})$ & $\mathrm{A} 1(\mathrm{~b})$ & $\mathrm{B} 1(\mathrm{~b})$ & $\mathrm{C} 1(\mathrm{~b})$ \\
\hline $150^{\circ} \mathrm{C}(\mathrm{c})$ & $\mathrm{A} 1(\mathrm{c})$ & $\mathrm{B} 1(\mathrm{c})$ & $\mathrm{C} 1(\mathrm{c})$ \\
\hline $160^{\circ} \mathrm{C}(\mathrm{a})$ & $\mathrm{A} 2(\mathrm{a})$ & $\mathrm{B} 2(\mathrm{a})$ & $\mathrm{C} 2(\mathrm{a})$ \\
\hline $160^{\circ} \mathrm{C}(\mathrm{b})$ & $\mathrm{A} 2(\mathrm{~b})$ & $\mathrm{B} 2(\mathrm{~b})$ & $\mathrm{C} 2(\mathrm{~b})$ \\
\hline $160^{\circ} \mathrm{C}(\mathrm{c})$ & $\mathrm{A} 2(\mathrm{c})$ & $\mathrm{B} 2(\mathrm{c})$ & $\mathrm{C} 2(\mathrm{c})$ \\
\hline $170^{\circ} \mathrm{C}(\mathrm{a})$ & $\mathrm{A} 3(\mathrm{a})$ & $\mathrm{B} 3(\mathrm{a})$ & $\mathrm{C} 3(\mathrm{a})$ \\
\hline $170^{\circ} \mathrm{C}(\mathrm{b})$ & $\mathrm{A} 3(\mathrm{~b})$ & $\mathrm{B} 3(\mathrm{~b})$ & $\mathrm{C} 3(\mathrm{~b})$ \\
\hline $170^{\circ} \mathrm{C}(\mathrm{c})$ & $\mathrm{A} 3(\mathrm{c})$ & $\mathrm{B} 3(\mathrm{c})$ & $\mathrm{C} 3(\mathrm{c})$ \\
\hline
\end{tabular}

Keterangan Kodefikasi :

- $\quad$ (a) = Spesimen coran 1

- $\quad$ (b) = Spesimen coran 2

- $\quad(\mathrm{c})=$ Spesimen coran 3

- $\mathrm{A} 1=$ Reduksi Penampang $5 \%$ dengan Temperatur $150^{\circ} \mathrm{C}$

- $\mathrm{A} 2=$ Reduksi Penampang $5 \%$ dengan Temperatur $160^{\circ} \mathrm{C}$

- $\mathrm{A} 3=$ Reduksi Penampang $5 \%$ dengan Temperatur $170^{\circ} \mathrm{C}$

- $\mathrm{B} 1=$ Reduksi Penampang $10 \%$ dengan Temperatur $150^{\circ} \mathrm{C}$ 
- $\quad \mathrm{B} 2=$ Reduksi Penampang $10 \%$ dengan Temperatur $160^{\circ} \mathrm{C}$

- $\mathrm{B} 3=$ Reduksi Penampang $10 \%$ dengan Temperatur $170^{\circ} \mathrm{C}$

- $\mathrm{C} 1=$ Reduksi Penampang $15 \%$ dengan Temperatur $150^{\circ} \mathrm{C}$

- $\mathrm{C} 2=$ Reduksi Penampang $15 \%$ dengan Temperatur $160^{\circ} \mathrm{C}$

- $\mathrm{C} 3=$ Reduksi Penampang $15 \%$ dengan Temperatur $170^{\circ} \mathrm{C}$

\section{Data Hasil Pengujian Keausan}

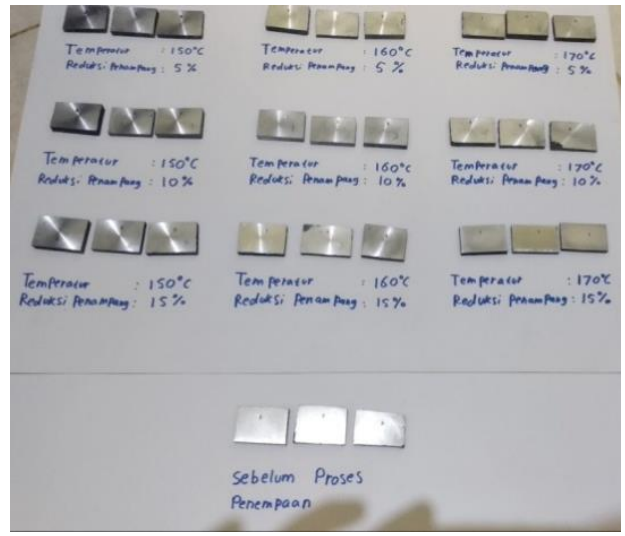

Gambar 3. Spesimen hasil uji keausan

Tabel 2. Hasil laju keausan

\begin{tabular}{|c|c|}
\hline Kodefikasi & Laju Keausan $\left(\mathrm{mm}^{3} / \mathrm{mm}\right)$ \\
\hline $\begin{array}{c}\text { Sebelum Proses } \\
\text { Penempaan }\end{array}$ & $0,054 \times 10^{-6}$ \\
\hline A1 & $0,038 \times 10^{-6}$ \\
\hline A2 & $0,035 \times 10^{-6}$ \\
\hline A3 & $0,030 \times 10^{-6}$ \\
\hline B1 & $0,034 \times 10^{-6}$ \\
\hline B2 & $0,029 \times 10^{-6}$ \\
\hline B3 & $0,027 \times 10^{-6}$ \\
\hline C1 & $0,026 \times 10^{-6}$ \\
\hline C2 & $0,018 \times 10^{-6}$ \\
\hline C3 & $0,004 \times 10^{-6}$ \\
\hline
\end{tabular}




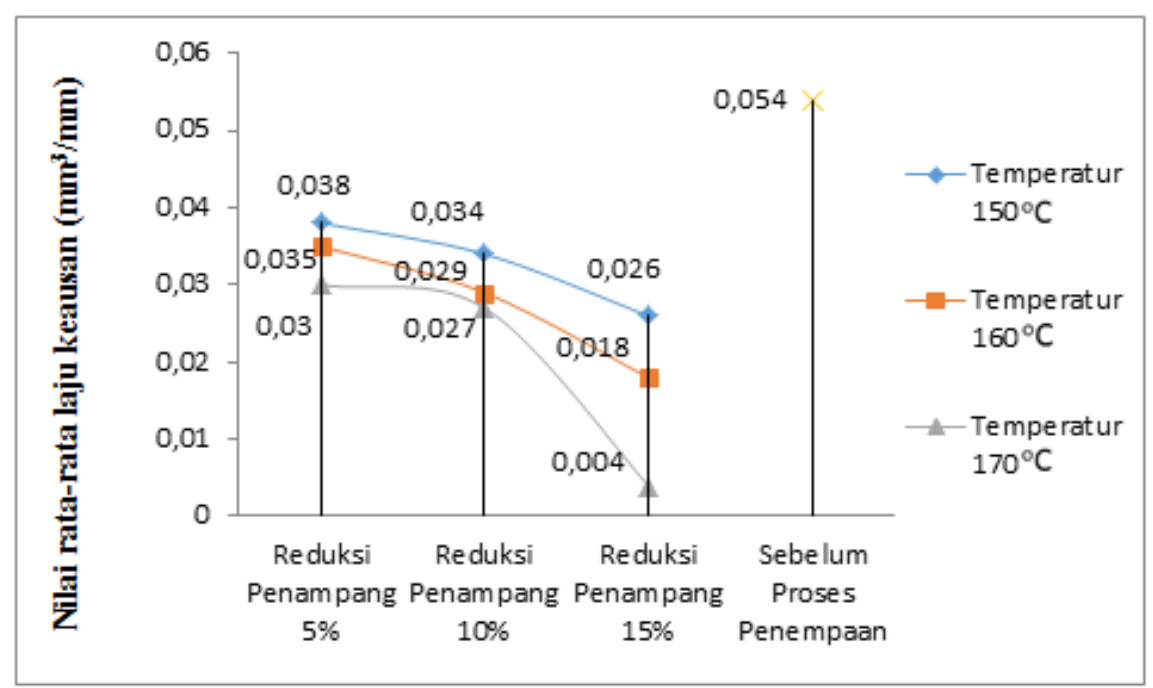

Gambar 4. Hubungan antara reduksi penampang terhadap laju keausan

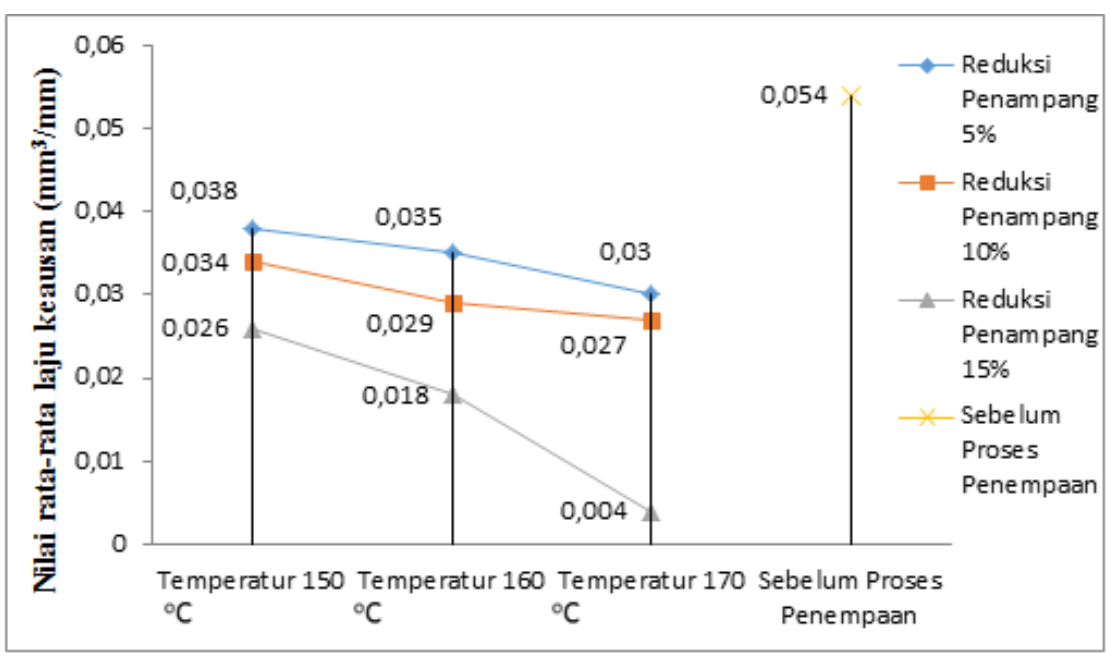

Gambar 5. Hubungan antara temperatur terhadap laju keausan

Pada gambar 2 dan 3. adalah analisa hubungan antara reduksi penampang dan temperatur terhadap laju keausan dengan hasil nilai laju keausan terendah pada sepesimen $\mathrm{C} 3$ dengan variasi temperatur $170^{\circ} \mathrm{C}$ dan reduksi penampang $15 \%$ dengan hasil $0,004 \times 10^{-6} \mathrm{~mm}^{3} / \mathrm{mmberbanding} \mathrm{terbalik} \mathrm{dengan} \mathrm{sebelum} \mathrm{proses}$ penempaan dimana ketahanan ausnya sangat rendah dengan nilai laju keausan pada spesimen sangat tinggi dengan hasil $0,054 \times 10^{-6} \mathrm{~mm}^{3} / \mathrm{mm}$.

\section{KESIMPULAN}

Uji keausan dan strukturmikro dapat dilihat bahwa variasi reduksi penampang sangat berpengaruh terhadap nilai laju keausan dan diameter rata-rata ukuran butir. Semakin besar reduksi penampang yang diberikan menghasilkan nilai laju keausan 
yang menurun dan ukuran diameter butir yang semakin kecil. Sedangkan hasil dari variasi temperatur pada proses penempaan juga sangat berpengaruh terhadap nilai laju keausan dan diameter rata-rata ukuran. Semakin besar temperatur yang diberikan menghasilkan nilai laju keausan yang menurun dan ukuran diameter butir yang semakin kecil. Meningkatkan temperatur pada spesimen membuat lebih padat dan lebih homogen serta memiliki sifat mekanik yang baik dan mengurangi porosity kecuali pada spesimen tanpa temperatur yang laju keausannya meningkat dan ukuran diameter butirnya lebih besar dibandingkan dengan menggunakan reduksi penampang.Setelah dilakukan proses penempaan nilai laju keausan semakin menurun.

\section{DAFTAR PUSTAKA}

[1] Gultom, E dan Kaelani, Y. "Studi Eksperimen dan Analisa Laju KeausanMaterial Alternatif pada Sepatu Rem Lokomotif”. Jurusan Teknik Mesin, Fakultas Teknologi Industri, Institut Teknologi Sepuluh Nopember Surabaya (ITS). 2016

[2] Ramnath, B. V., Elanchezhian, C., Annamalai, R. M., Aravind, S., Atreya, T. S. A., Vignesh, V and Subramanian, C. "Aluminium Metal Matrix Composites - A Review".Department of Mechanical Engineering, Shinas College of Technology, Oman. 2013

[3] Setiawan, A., Nilasari, A. R., Ari, M. “Analisa Sifat Mekanik Komposit Al-2075 Reinforcement Dengan Electroless Abu Dasar Batubara". Politeknik Perkapalan Negeri Surabaya.2016

[4] Ahmad, Z., Santoso, E. "Strukturmikro Coran Komposit Al 6061+Abu Dasar Batubara Setelah Perlakuan T6. Jurnal Penelitian Fakultas Teknik, Vol 01, pp.101-102. 2015

[5] Nafi, M dan Wahid, I. "Effect of T6 Heat Treatment on Mechanical Properties of Coal Ash Aluminum Composite as Brake Disk Holder Component". Buku Prosiding Seminar Nasional Tahunan Teknik Mesin (SNTTM) ke XVI 2017. MT-03.Institut Teknologi Sepuluh Nopember Surabaya. 2017. 12-14

[6] Maulana, A."Pengujian Keausan Komposit Aluminium Dioerkuat Karbon Nanotube dan Alumiinium Diperkuat Silikon Karbida”. Jurusan Teknik Mesin. Fakultas Teknik. Universitas Diponegoro. Semarang. 2012 
[7] Atmadja, S. T., Sulardjaka. "Uji Keausan Bahan Komposit Aluminium Fly Ash terhadap Besi Cor Kelabu Pada Temperatur Kamar dan Temperatur Tinggi”.Program Studi Teknik Mesin, Fakultas Teknik Universitas Diponegoro Semarang. 2018

[8] Susanto, J., Seputro, H., Santoso, E. “Analisa Pengaruh Variasi Media Pendingin dan Waktu Aging Pada Perlakuan Panas T6 Terhadap Strukturmikro Komposit Aluminium Abu Dasar Batubara”. Universitas 17 Agustus 1945 Surabaya. 2016

[9] Rusianto, T.” Hot Pressing Metalurgi Serbuk Alumnium Dengan Variasi Suhu Pemanas". Teknik Mesin, Fakultas Teknologi Industri. Institut Sains Teknologi AKPRIND Yogyakarta.2009 